\title{
SYSTEM OF POLITICAL GOVERNANCE AND PUBLIC SERVICE DELIVERY IN SINDH, PAKISTAN
}

\author{
Allah Dino ${ }^{*}$, Prof. Dr Imdad Hussain Sahito ${ }^{\dagger}$ \\ \& Prof. Dr. Amir Ahmed Khuhro*
}

\begin{abstract}
Local government systems are considered the primary governance level in terms of democracies, though, their contribution to governance is wellestablished. Concerning this, the present study aims to assess the local government concerning the province of Sindh Pakistan. The focus of this study is to highlight the efficacy as well as the efficiency of the restructuring of the government office. For conducting this study, an experimental research design based on the qualitative research approach is used. The findings of the study conclude that the empowerment of the local government is closely related to the enhanced work practices and better attainment of the economic goals. It also shows that this assists in better management as well as reduction of conflict, since they are more aware of the problems. Therefore, more authority should be provided to these local governments for ensuring the welfare of the people, and Pakistan as a whole.
\end{abstract}

Keywords: Local Governments, Governance, Sindh, Pakistan, Qualitative Study

\section{Introduction}

It is widely acknowledged that the local government system is integral for enhancing the citizens' living standard, given its tendency to be closer to the development needs (Soomro, and Chandio, 2013). Another study of

\footnotetext{
* PhD. Student, Department of Pakistan Studies, Shah Abdul Latif University, Khairpur. Email: admangrio@gmail.com

$\dagger$ Dean Faculty of Social Sciences, Shah Abdul Latif University, Khairpur. Email:imdad.sahito@salu.edu.pk

* Institute of International Relations, Shah Abdul Latif University, Khairpur. Email:amir.khuro@salu.edu.pk
} 
Jabeen (2019) highlights, that local government is critical as it assists in shaping the development agendas, which help explain the government implications programs to the general masses. In 2017, the province had a population of 47 million, which ranks it second among the provinces in the country. Administratively, the region has seven divisions and twenty-nine districts (Rid and Murtaza, 2019). Various studies emphasize that ironically, Sindh is the only Province in Pakistan, which comprise of a local government system (Warriach, 2019; Rid and Murtaza, 2019). The remaining others have either elections or are introduced through amendments in law. Numerous scholars have advocated that this indecisiveness is what accounts for the glitches in the governance.

The local government system in Sindh, Pakistan was introduced in 2013, following its actual implementation in 2016, which is integral but a delayed step for enhancing the delivery of local services in Sindh (Murtazaand Pakistan, 2017). The deployment of the local government has served as a primary ownership driving tool (Rid and Murtaza, 2019). This system has led to the elections being held on the party basis, where sound labour division is provided for the legislation along with the clear, authoritative line.

However, the empirical findings provide that decentralization of the local government power needs further investigation for achieving optimized technocratic as well as political-economic goals (Rid and Murtaza, 2019; Murtazaand Pakistan, 2017). Therefore, the purpose of this work is to highlight the areas, where more work must be carried for Sindh LGOs empowerment. Most studies highlight that the gap that prevails is the presentation of a comprehensive analytical framework, which helps enlighten the devolution type as per the global experiences concerning local governance as well as the academic literature on local government. This provided framework could assist in the identification of the authorities, functions, and more for giving access to a more developed LG system, which is lacking in the Sindh. It also assists in providing a roadmap to construction.

\section{Research Objectives}

- To outline the local government system concerning Sindh, Pakistan.

- To study the local government's practice without governance in Sindh, Pakistan.

\section{Research Methodology}

\section{Research Design}

The research design employed in this study is exploratory. Generally, it is defined as the strategy which facilitates the drawing of useful and valuable results in a comprehensive manner. Another reason for selecting this research 
design is that previous researches have also found it helpful in drawing complete results (Murtazaand Pakistan, 2017; Pascoeand Jones, 2019).

\section{Research Approach}

The research approach is the strategy that is used for gathering the results. Generally, two types of research approaches are observed; qualitative and quantitative methods (Tuffour, 2017). The one used in this study is qualitative, precisely, secondary quantitative data, which is focused on the gathering of the qualitative data, which enables the research to analyze the results profoundly.

\section{Research Population}

The population in the research refers to the sources that integrate into content that precisely represent deals with the governance related to Sindh, Pakistan. The selection of these sources was based on the non-random sampling procedure, primarily, on the purposive sampling method, where the sources are recruited based on the determined study protocols. The protocols determined for this research are depicted in Table (1), as;

\section{Table 1: Criteria for Including the Studies}

\begin{tabular}{|l|l|}
\hline Inclusion Criteria & Exclusion Criteria \\
\hline Content related to Sindh Governance & $\begin{array}{l}\text { Content not related to Sindh } \\
\text { Governance }\end{array}$ \\
\hline $\begin{array}{l}\text { Scholarly Articles related to } \\
\text { Emerald, Taylor, and more }\end{array}$ & Blogs Post and Websites \\
\hline Official Government Websites & Essays, Wikipedia \\
\hline News Reporting Sources & General Comments and Opinions \\
\hline Time of Publish from 2011 to 2020 & $\begin{array}{l}\text { Time of Publish from other than } \\
\text { 2011 to 2020. }\end{array}$ \\
\hline English language & Language other than English \\
\hline
\end{tabular}

\section{Data Collection and Analysis}

The different online database are used for searching the relevant articles. Most of these were derived from the Google Scholar, along with Scopus and more, which are considered as authentic sources for drawing results. The analysis is held by understanding the pattern of the data incorporated, which aids in answering the determined research question.

\section{Findings}

The local government system is observed to develop the link between the people and the government (Akbar, 2018). Although it has been highly acknowledged that local government integrates into different authorities and 
responsibilities for planning; roads and traffic; housing; environment; economic and community development; fire services; recreation and amenity services; as well as maintaining the elector's register. Also, given the proximity to the individuals, these have a better capacity for deploying the necessary measures. Initially, the concept has been linked to the decentralization aspect, though various governmental issues prevail concerning the limitation of the governance of local government (Murtaza, and Pakistan, 2017). Rid and Murtaza (2019) argues that the government that practices the decentralized system is likely to help sustain as well as support local governance institutions.Local officials are made unable to ask questions about the continued flow of opportunities, resources and their accompanying recommendations and evaluations as nobody is seen as an individual who stops the aid as required by the culture of the civil service (Rid and Murtaza, 2019). To increase alignment, ownership, harmonization, mutual accountability and managing for results, there exist calls for change in donor orientation to aid effectiveness. Akbar (2018) analyzed that there will be difficulty in achieving the declaration objectives, and they have been seen to be off-track. They prove to be authoritarian towards states, and there is not enough binding of donor-driven and developing partners (Shaheen, 2018).

\section{Political Analysis}

For Sindh financial and political devolution and genuine administrations to local government, it is essential as compared to other provinces of Pakistan because of two main factors (Zaidi, 2019). Sindh is the secondlargest industrial province of Pakistan and after Punjab, and it has advanced service economy. All the major industries are located in Karachi, which is the prime commercial city of Pakistan, and it has two commercial seaportsKarachi port and Port-Bin Qasim (Amjad, Rasheed, and Baig, 2016). The rest of the economy depends on the agriculture sector. The political explosive ethnic division has over-laid this economic division (Rid and Murtaza, 2019). Mohajirs dominate Hyderabad and Karachi, which are the next largest cities, mahajirs are the non-Punjabi immigrants who came to Pakistan from India after independence in 1947. Karachi also hosts millions of Pakthun immigrants from KP province and immigrants from Punjab known as Punjabi. Indigenous Sindhis control smaller rural areas and towns. It has been felt by PPP political party that their powers have been denied at the federal level on many occasions by the Punjabis who dominate the establishment of the state and it is the prominent bearer of Sindhi grievances of being marginalized within the state, especially by Punjab (Rid and Murtaza, 2019). Sindhi also feels that they became a minority because of the migrations of mohajirs from India after 1947 and further migrations from upcountry, and they both situated into Karachi. For Mohajir grievances, MQM is the prominent bearer, who always complains about being 
marginalized by both PPP provincially and Punjab dominates nationally Pakistani establishment. Finally, Pakhtun and Punjabi become the ethnic minorities in Karachi. They usually complain about suffering triply. The suffering of the minority groups, as well as Sindh's government, is deteriorating condition due to ignorance towards Karachi.

\section{Living Conditions Analysis}

Rid and Murtaza (2019) analyzed that there is widespread, profound and severe poverty in Sindh. According to Akhtar and Jariko (2018), the majority of the population which is living under the poverty line increased. Solomon (2019) assessed that rural area is the residence of the majority of the poors. It is examined that there has been a plunge in resources since 2005 which used to address poverty at the local level, the value of fixed rates has also been decreased due to inflation as this proves to be troublesome because there was no ability of assemblies so that their rates can be raised without counsellors (Ahmad, Oxley, and Ma, 2020; Desk, 2020).

\section{Administrative Conditions Analysis}

Murtaza and Pakistan (2017) highlight that the administrative power was re-presented to the province in 2013. It includes aspects such as substantial local development, building control, and police regulation. The assigning of the authority to the local government further led to the change of Police Ordinance of 2002 to the colonial-era Police Act 1861. However, the provincial government is not provided with the authorities for regulating the Karachi Development Authority, the Hyderabad Development Authority, and other similar development authorities. Act section 74 has also highlighted to take over the assigned functions of local government, thus limiting the governance capacity.

\section{Uncertainty}

There exists an uncertain situation in future local government despite the hope from proactive LGs role because the same institutional problems still haunt the system which is responsible for such standstill. However, political parties came into power again alongside a majority government, in particular, after the elections. The PPP would call for the elections of local government because expectations that the minority government's political machinations characterized by the parliament were over. To suffocate the local system of government further, the government did not do so and used its large numbers in parliament.

\section{Functioning Authority}

As per Rid and Murtaza (2019), a constitutional amendment bill is needed to empower the president so that the actual date would be decided for holding local polls as compared to particular dates prior specified in the 
constitution. Soomro and Chandio (2013) expressed its dangers, as according to them room for dictatorship would take place by the new law as well as local assemblies' death over a period particularly in those areas where there is no guarantee, by the sitting president, of his party's victory in the polls. It described that their MPs betrayed them. This system would be responsible for taking the people to the system where choices are made by one person only, and they did not want such a system. To further constrain the governance functions of local governments, there exists another bill of an amendment that is to be tabled yet in the parliament alongside provisions. Government (2010) reported that the removal of the policy making's function from the responsibilities of counsellors as well as making MPs voting they include members of the councils.

\section{Centralization}

It means that MPs have the right to take decision-related to local governance issues and policy formulation at the local level with an effectiveness that will result in centralization if these amendments are passed (Bakhsh, 2018). Also, the country is dependent on donors that without their support, it is not able to operate fully as there is the prevalence of coercive pressures that are set to continue. Chiweza (2016) analyzed that the donors provide most of the development budget and $50 \%$ of its annual recurrent costs. Room for coercive isomorphism pressures is given by this high donor dependence that impacts the local governance of the state. As per the International Development Agency, one of the donors mentioned that the heavy reliance on the help of donor leads to the need for dialogue and development trends can be positively influenced.

\section{Governance Model}

The study of Murtaza (2017), had defined that local government works along with the contribution as well as the cooperation of people. Thus, the effectiveness of the local governments in Sindh can improve significantly by involving the local communities in local officials (Jabeen, 2018). It implies that a participatory governance model could enhance and maximize the governance of the local governments and their services in Sindh. In addition to this, likewise, the study of Idris (2016), explained that adoption of mechanisms such that decentralization which includes the proper functioning of the central government and empowering the local authority with the effective voice, could enhance the involvement of local government in almost all the sections of state or society in Sindh province. To enhance participation and collaboration, the study of Khan, Reḥman, and Ashfāq (2016), had defined that the establishment of decentralization in the Sindh province can help stakeholders to participate in the integral practices of the decentralization policy. 


\section{Reflections and Summary}

There are no suitable representatives who can push development programs at the grassroots level, which tend to increase poverty and inequality. According to Hussain and Ismail (2020), local government in the rural areas highlighted that some of the villagers faced problems reaching out to the closest clinic, in the rainy season particularly, because there was no bridge to cross a river as it was impossible to travel along. Due to the inability to reach the clinic, some of the villagers had died with the ailment. As quoted in Ngozo (2009), to facilitate that a bridge should be constructed where there exist no local authorities. Yusufand Hasan (2015) district echoed these sentiments, and according to him, people were not able to drink safe water as many areas did not have boreholes. As quoted in Yusufand Hasan (2015), as there are no councilors who can push for various developments, the process of decentralization that permits communities to get access for money for many development projects is time taking. As per the demonstration of the Sindh experiment, there has been a worsening of the situation on the ground as local governance paralysis in the contexts of politics is marked by wide inequality, systematic marginalization, and structural poverty.

\section{Discussion and Recommendations}

It is an important exercise for Pakistani policymakers to understand the conflict in Sindh. For many reasons, these conflicts are observed in the international community and the United States. The evolving security condition of Sindh highly influences the security and stable situation of Karachi and for the national economy it has the broader implications and vice versa. In May 2017, the Tehreek-e-Insaaf political party came to power in the country. It had made all possible efforts to highlight ethno-political violence, extortion, terrorism and crime that have raised since 2008 in Karachi.

The paramilitary Rangers have led the security operations started in September, 2013, due to this operation more than 1800 criminals and terrorists were arrested by March, 2014. In August, 2014, the new appointment of senior police officials took place that fizzled the operation, the provisional political parties, and their interference, and the vision of the federal government was lacking. However, there is always a need to stabilize Karachi urgently, in this section it is essential for policymakers to get aware of conflict dynamics in other provinces that are contributing to crime and violence in Karachi (Yusufand Hasan, 2015). The Sindh government has desired to attract foreign investment to establish wind power corridors in the province to make eco-friendly fuel sources for our power plan, and it is done 
at the provincial level. For example, a $\$ 1$ billion amount was secured by governments from Chinese investors who are sponsoring the wind power plant project, which can be developed in the Jhampeer corridor in Jamshoro and Thatta districts and 650 megawatts were contributed to the national grid. More than $60 \%$ of the oil field is located in Sindh, similarly $44 \%$ of its gas fields, $56 \%$ of the states' oil productions and $55 \%$ of its gas production. However, the terrible security situation in Sindh may impede production in the energy sector as it has Baluchistan provinces as its neighbours, where on daily basis separatists target energy infrastructure and some other commercial projects and compromise the national economy and also interprovincial ties, which effect the annual loss gross domestic products (Ridand Murtaza, 2019).

On contrary to this, the study of Jabeen (2018), had defined that the current Prime Minister of Pakistan namely 'Imran Khan', has always been the biggest supporter of the local government system. From the study of Jabeen (2018), it has determined that; from the views and interview of Imran Khan, it was reported that the current government is in favor of the local government system through providing governance to the different people within the designation of local governments. On the other side, the study of Murtaza (2017), had defined that the main purpose of the local government system in Sindh, is to provide as well as maintain a properly organized system where people like councilors perform actions to engage the whole activities or surrounding environment as a part of their duty. Local government system governance is liable to perform their practices regarding the improvements of social, economic and the overall environment to give benefits, safety, and security to the society or state. It is true that local governments which strongly ensure the provision of the overall quality of the individual's life and must fulfill their commitments (Idris, 2016; Khan, Reḥman and Ashfāq, 2016; Brown and Ahmed, 2016; Nadeem, 2016; Rid and Murtaza, 2019).

The studies of (Idris); Khan, Reḥman and Ashfāq, (2016); Brown and Ahmed, (2016); Nadeem, (2016); Rid and Murtaza, (2019), had defined that the local government in Sindh has lack of the Capacity-building local officials or the local appointed officials are not elected relatively. They are not well equipped with the required skills and abilities necessary to run the essential operations within the different cities or geographic areas of Sindh. Local officials are not well-aware of policymaking, its evaluation, and implementation (Murtaza, 2017). Most of the Sindh cases include decentralization which shows the effect from a specific date but without the preparedness tactics or practices of the local governments of Sindh to push forward the mandate of decentralization only (Jabeen, 2018). According to the study of Jabeen (2018), it was reported that decentralization must be introduced in a phased manner to increase the institutional capacity of the local governments in Sindh and to make adjustments simultaneously 
according to the emerging challenges. In this regard, the central authority in contribution with the local governments' system is liable to formulate the policy of decentralization to devise the capacity-building mechanism among the local governments of Sindh (Idris, 2016). The local government of Sindh needs training related to various essential practices to improve the local government's governance system (Idris, 2016). The local officials need training from different resources like nationals, private and overseas training institutions.

Moreover, an analysis was done to examine the evolving security condition in Sindh. It can help both to recognize the elements that enable violent extremism to highlight opportunities to spread. Those districts which are outside of Karachi remain free from extremist violence that has disturbed the other part of the state, such as FATA (Federally Administered Tribal Areas) and KPK. Thus the violent extremist incidents though raised in the number of alarming paces, are by no means of rules and norms. Sindh encourages the lawmakers to avail some opportunities to implement such policies to observe the spread of violent crime and extremism in the province and before it damages the society more. At the end of this section, the researcher reported and even identified the elements that make the Sindh vulnerable to promote extremism. It includes the inadequate service delivery, and poor governance, changes are made in the Sindh's feudal culture, the development of democratic institution but now it starts leaving an institutional vacuum or eroding, the politicization of civil law enforcing agencies, such as underdevelopment, widely spread poverty and fails to establish an educational system of provinces.

A functional local government system, for transparency, grassroot participation, and accountability, are required by democratic governance. According to Malik and Rana (2020), in a scenario like this councilor plays a crucial role, and their presence around the clock leads to democracy in a democratic society like this one. As per Meenakshi and Saxena (2020), democracy suffers if there is the absence of councilors and according to a big democratic deficit is represented by it. There should be the availability of councilors to make the democracy consolidated and successful.

\section{Limitation and Future Studies}

The findings of this study are limited due to its restriction to a specific region. The focus on just province Sindh serves as a significant hindering block in its results generalizability, as these cannot be deployed to other areas based on the different socio-economic characteristics. Similarly, the use of qualitative study approach limits research ability to reach a far impacting finding. Thereby, future researches should explore other provinces across different countries to help improve the study 
generalizability. Also, they must consider the use of different methods for drawing quantifiable findings.

\section{Conclusion}

The review of the secondary sources has provided and emphasized the need that the local government though present in the Sindh lacks the governing authority, which is integral for drawing comprehensive results. The outcomes have argued the need to decentralized more for the integration of transparent operations, which leads towards regional stability. The findings are likely to assist in reducing the extremist group prevalence in the region.

\section{References}

Ahmad, M.I., Oxley, L., and Ma, H. (2020). What Makes Farmers Exit Farming: A Case Study of Sindh Province, Pakistan. Sustainability, 12(8), 3160.

Akbar, N. (2018). Commonwealth Local Government Forum's support of Local Councils Associations in Pakistan. Commonwealth Journal of Local Governance, ID-6727.

Akhtar, S., and Jariko, G.A. (2018). Socio-Economic Characteristics of Poverty and Their Impact on Seasonal Migration in Tharparkar District, Sindh, Pakistan: A Logistic Regression Analysis. Grassroots, 52(1).

Amjad, S., Rasheed, M.A., and Baig, M.A. (2016). Mangrove Ecosystem Services: Indus Delta (PQA), Sindh. Journal of Geoscience and Environment Protection, 4(7), 179-184.

Bakhsh, M.A. (2018). Politics-Bureaucracy Relations in Pakistan: A Case of Local Government. Governance, 3(1), 1-13.

Chiweza, A.L. (2016). The political economy of fiscal decentralisation: Implications on local governance and public service delivery. In Political Transition and Inclusive Development in Malawi (pp. 111127). Routledge.

Desk. (2020). SHC seeks Sindh's reply over local council polls on March 10. Available at: https://arynews.tv/en/local-bodies-election-shc-seekssindh-govt-reply/

Hussain, M. and Ismail, M., (2020). Decentralization, participation, devolution and infrastructure development in rural areas: A case study of district Bhakkar, Pakistan. Asian Journal of Comparative Politics, 2057891119900674.

Jabeen, M., (2019). The Local Government System of Pakistan: Participation, Representation and Empowerment of Women. Pakistan Perspectives, 24(1). 
Malik, N. and Rana, A., (2020). Civil society in Pakistan: an exclusive discourse of projectization. Dialectical Anthropology, 44(1), 41-56.

Meenakshi, M.R.S. and Saxena, S., (2020). A Journey of Decentralisation in South Asia. Studies in Indian Place Names, 40(10), 835-841.

Murtaza, N. and Pakistan, I. N. S. P. I. R. I. N. G. 2017. Undermining Local Governance: A Review of the Sindh Local Government System, 2013. Karachi: Pakistan Institute of Labour Education and Research.

Ngozo, C. (2009). Malawi Non-Voters to be Denied Needed Farm Subsidies. Global Information Network/Inter-Press Agency. New York, 25.

Pascoe, P. and Jones, S.J. (2019). Exploratory versus experimental design: overcoming the prejudice of 'data dredging'. International Journal of Population Data Science, 4(3).

Rid, S.A. and Murtaza, N. (2019). The Local Government System in Sindh: A Critical Analysis of The Sindh Local Government Act 2013. The Government-Annual Research Journal of Political Science., 7(7).

Shaheen, F. (2018). Comparing informal sector engagement across Pakistan's largest urban centers: Lessons in state and non-state engagement from Karachi and Lahore. In Metropolitan Governance in Asia and the Pacific Rim (pp. 95-122). Springer, Singapore.

Solomon, S. (2019). Understanding the Impacts of Climate Change on Water Access and the Lives of Women in Tharparkar District, Sindh Province, Pakistan: A Literature Review, 1990-2018.

Soomro, A.N. and Chandio, A.A. (2013). Challenges to Good Governance: A Case Study of Issues in Local Government System of Pakistan. Journal of African and Asian Local Government Studies, 2(4).

Tuffour, I. (2017). A critical overview of interpretative phenomenological analysis: a contemporary qualitative research approach. Journal of Healthcare Communications, 2(4), 52.

Warriach, S. (2019). Pakistan's troubled local governance [Online]. Available at: https://www.thenews.com.pk/tns/detail/568736-pakistanstroubled-local-governance

Yusuf, H. and Hasan, S.S. (2015). Conflict dynamics in Sindh. United States Institute of Peace.

Zaidi, S.S.Z. (2019). Local Government Under Army Rule: A Comparative Analysis of Zia ul Haq and Pervez Musharraf Local Government System. 